\title{
Atestado de Exclusão Com Firma Reconhecida: O Sofrimento do Presidiário Brasileiro
}

Notarized exclusion certificate: the suffering of the Brazilian inmate

Resumo: $O$ presente trabalho trata a problemática da pena de prisão no Brasil partindo da discussão acerca do processo sociohistórico da exclusão social, e analisa o sofrimento que acomete os presidiários pela privação de poder de construção de novas perspectivas de vida. Revisando estudos sobre a produção da criminalidade na atualidade e sobre o sistema carcerário brasileiro, conclui-se que as prisões no Brasil operam como mecanismo de oficialização da exclusão que paira sobre as camadas populares.

Palavras-Chave: Exclusão social, presidiário, prisão, criminalidade.

Abstract: The present work deals with the problems involving the imprisonment sentence in Brazil stemming from the discussion about sociohistorical process of social exclusion, and analyzes the suffering which overtakes the inmates by the privation of the power of construction of new perspectives in life. Revising studies on the current production of criminality and on the Brazilian prison system, it was concluded that prisons in Brazil operate as a mechanism that makes official the exclusion that already occurs towards the lower income classes.

Key Words: Social exclusion, inmate, prison, criminality.

\section{Gilead Marchezi \\ Tavares \& Paulo Rogério Meira Menandro
Programa de Pós- Graduação em Psicologia da Universidade Federal do Espírito Santo.

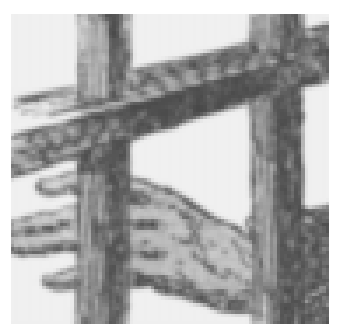

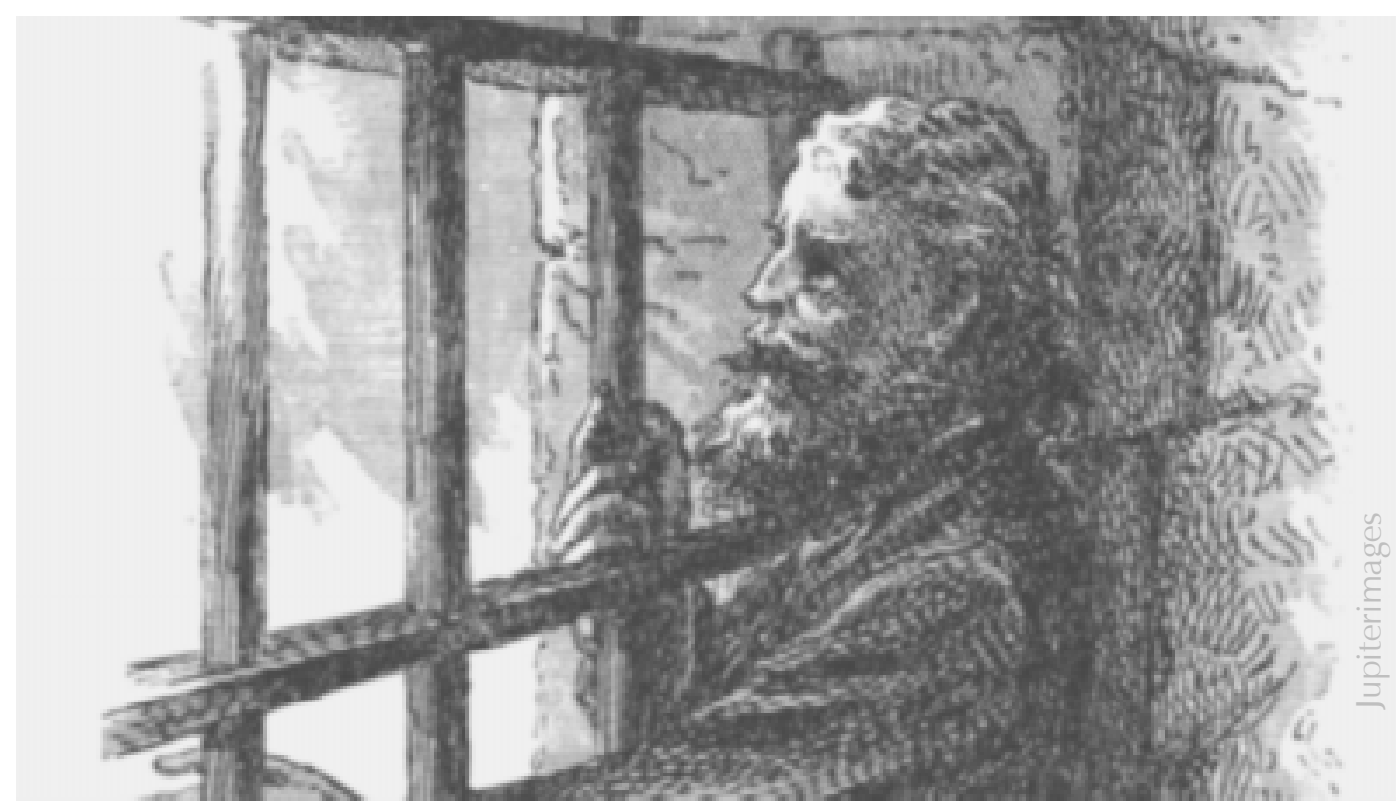

O estudo de questões relativas à criminalidade violenta, hoje, no Brasil, tem sido marcado pelas reflexões acerca da exclusão social e das relações sociais mediadas pela violência. Em nosso cotidiano, a violência manifesta-se de inúmeras formas e, em alguns casos, não causa reação de perplexidade entre as pessoas, mas, sim, de conformidade. A exclusão social é uma das manifestações mais violentas contra indivíduos em nossa sociedade, uma vez que produz a carência de qualquer horizonte de perspectivas e uma "privação de poder de ação e representação" (expressão usada por Wanderley, 1999).
Ao tomarmos como foco de atenção os indivíduos confinados em presídios, realizamos uma ampliação do tema e dos problemas sociais mencionados acima. As prisões brasileiras funcionam como mecanismo de oficialização da exclusão que já paira sobre os detentos, como um atestado de exclusão com firma reconhecida. Dizemos isso não só considerando o estado de precariedade atual das prisões, mas também o estado de precariedade em que se encontram os indivíduos antes do encarceramento - em sua maioria, provenientes de grupos marcados pela exclusão (é possível observar tal tipo de conclusão 
em Fragoso, 1977; Thompson, 1983; Benevides, 1983 e, ainda, em análise do censo penitenciário de 1996, de São Paulo, realizado por Kahn, 1997). Que tipo de perspectiva de vida pode vislumbrar um indivíduo que passa por tantas precariedades e privações infligidas pelo sistema socioeconômico?

O sistema econômico-político aí implicado, que sempre produziu meios de conservação da ordem pública (e de classe) e de contenção da violência, reduzindo o fenômeno à esfera do invisível ou do exclusivamente individual, parece ter perdido as rédeas nessa passagem de milênio com a consolidação do neoliberalismo econômico - ou tal condição pode ser mais uma estratégia políticoeconômica. É tanto que a segurança pública é o tema principal de discussão em muitas partes do mundo, segundo Wacquant (2001).

O mundo novo que se apresenta (que, na verdade, já vinha sendo construído ao longo de muitos anos), com suas numerosas facetas, desvela uma multiplicidade de desejos, prazeres, personagens, quase nunca acessíveis à maior parte da população brasileira. Nesse frenesi em busca da "felicidade via posse de bens" que a economia neoliberal proporciona, são os jovens os mais afetados (os gatos que ainda não foram escaldados). $O$ envolvimento juvenil em práticas violentas ou perigosas tem sido alvo de pesquisas no mundo inteiro (Peralva, 1996; Jankowski, 1991; Zaluar, 1996a e 1996b). Na América Latina, o envolvimento dessa população com o tráfico de drogas ilícitas preocupa de forma particular. Ora, a desigualdade social (em nosso país, uma das maiores do mundo), que anda a par da exclusão social, marca o cotidiano dos jovens que podem ver, nas práticas de risco, uma oportunidade para se sentirem incluídos no único mundo apresentado como desejável, ou seja, aquele dos prazeres sem limite. Tais práticas, por outro lado, remetem-nos, inevitavelmente, à percepção de que estão fora, à margem.

A hipótese que apresentamos a partir da abordagem da vida de presidiários no Brasil segue o seguinte raciocínio: quando um indivíduo, vivendo e sofrendo a exclusão, torna-se um infrator típico, as condições excludentes continuam intactas na organização social. Quando ele se torna um presidiário típico (caso não tenha se tornado antes um típico jovem infrator assassinado - uma exclusão literal), as condições excludentes continuam intactas na organização social e se fazem presentes, também, ainda que de outras formas, nas relações sociais travadas na instituição do encarceramento. Quando ele cumpre sua pena e se torna um ex-presidiário típico, a sociedade à qual ele deverá retornar ainda mantém suas condições excludentes intactas. $\bigcirc$ que estamos querendo dizer é que a prisão, nas condições socioeconômicas ou prisionais brasileiras, até pode mudar alguma coisa no indivíduo que nela vive, mas não altera a perspectiva com a qual o detento convive, a de que as condições sociais do seu passado estarão novamente presentes no seu futuro.

\section{A Produção da Criminalidade}

A segurança pública é um dos temas mais discutidos, hoje, no País. No Estado do Rio de Janeiro, por exemplo, o problema da criminalidade relacionada ao tráfico de drogas parece ter tomado, de vez, a cena. Há pouco tempo, era possível ler, toda semana, alguma notícia nos jornais sobre fechamento de escolas, estabelecimentos comerciais ou vias públicas por ordem de "comandantes" do tráfico no Rio de Janeiro. Na campanha para a sucessão presidencial, ocorrida no ano 2002, o plano mais requisitado pelos eleitores, repórteres e opositores foi o da intervenção programada para o combate à criminalidade. Notável (ainda que requentada) foi a presença da idéia de endurecimento contra o crime com medidas de segurança, que vão desde um aparato policial vigoroso a um sistema punitivo impiedoso, tanto por parte de programas de governo como por parte da opinião pública.

Wacquant (2001) faz-nos pensar que o sentimento de insegurança e o foco da atenção voltada primordialmente para a violência são fenômenos mundiais ampliados pelo processo neoliberal de globalização da economia:

A penalidade neoliberal apresenta o seguinte paradoxo: pretende remediar com um "mais Estado" policial e penitenciário o "menos Estado" econômico e social que é a própria causa [grifo do autor] da escalada generalizada da insegurança objetiva e subjetiva em todos os países, tanto do Primeiro como do Segundo Mundo (Wacquant, 2001, p. 07).

Vê-se a perversão da penalidade neoliberal, segundo o autor, quando aplicada a países com grande desigualdade de condições e de oportunidades, sem tradição democrática, e, no caso brasileiro em particular, com uma concepção hierárquica de cidadania - em que todos são iguais, mas uns são mais iguais que outros - que faz confundir a manutenção da ordem pública com a manutenção da ordem de classe. Nesse sentido, o investimento no Estado penal com a intensificação da intervenção do aparelho policial e judiciário é o mesmo que implementar uma verdadeira ditadura sobre os pobres (p.10).

\section{A penalidade neoliberal apresenta o seguinte paradoxo: pretende remediar com um "mais Estado" policial e penitenciário o "menos Estado" econômico e social que é a própria causa [grifo do autor] da escalada generalizada da insegurança objetiva e subjetiva em todos os países, tanto do Primeiro como do Segundo Mundo}

Wacquant 


\section{As ideologias individualistas}

O aumento da criminalidade violenta a partir da década de 80, no Brasil, e, particularmente, o envolvimento de jovens em atividades violentas e, em grande parte, criminosas (Adorno e Cardia, 1999; Zaluar, 1996a e 1996b; Peralva, 1996) favoreceram o surgimento de questões penitenciárias exacerbadas, atualmente, como a superlotação carcerária e o elevado número de jovens detentos.

Velho (1996) faz referência à ausência de um sistema de reciprocidade eficiente, ausência essa expressada pela desigualdade social que produz a violência. "A impossibilidade de acesso da grande maioria das camadas populares a bens e valores largamente publicizados, através da mídia e da cultura de massas em geral, acirra a tensão e o ódio sociais" (Velho, 1996, p. 19). A deficiência do sistema de trocas coletivas teria origem na modernização, com o crescimento das grandes cidades, que desorganizou o sistema de valores e relações sociais e deu espaço para ideologias individualistas. Estas, por sua vez, transfiguraram os contatos sociais, neles imprimindo um caráter de impessoalidade que banalizou a violência física como marca do cotidiano.

Seguindo a mesma linha de pensamento, Zaluar (1996a) afirma que um dos pontos principais da questão reside no enfraquecimento dos laços de lealdade e de dependência entre pais e filhos, padrinhos e afilhados, patronos e clientes. Tal empobrecimento dos mecanismos tradicionais de socialização da juventude desencadeou uma crise de valores que deu lugar à interiorização de uma ideologia individualista moderna, cuja máxima é a independência do sujeito, com um ideal de liberdade exacerbado, em que a noção de direitos se consome na inexistência de vínculos sociais com seus iguais.

Nesse contexto, o bandido emerge como figura masculina potente, que resolve tudo pela sua própria cabeça, mas que, "no entanto, não deixa de ser um eu convencional, dependente que está dessa imagem de virilidade e das regras para afirmála, derivadas, por sua vez, da instrumentalidade do mercado" (Zaluar, 1996a, p. 101). Assim, o bandido precisa ser mau, precisa ter disposição para matar, para se auto-afirmar como "macho" nessa construção social baseada na violência mediadora das relações sociais.

O tráfico de drogas encontrou lugar certo na lógica cultural da individualidade e da necessidade do consumo. Produzindo a ilusão do ganhar dinheiro regras sociais, o crime organizado em torno do tráfico de entorpecentes captura os jovens moradores dos bairros empobrecidos.

Seu consumo passa a ser uma cópia exagerada, orgiástica, do que entende ser o luxo do rico: muita roupa, carros, mulheres, uísque ("bebida de bacana") e muita cocaína ("coisa de gente fina"). [...] ilude-se com a possibilidade, enfim, de que, apesar de jovem, preto e pobre, vai se "dar bem" e sair dessa vida de perigos e medos. Na verdade, a quase totalidade desses jovens ou morre muito cedo, muitas vezes caçados por outros bandidos ou por policiais de extorsão, porque enriquecem mais do que deviam, ou é presa e passa a viver os horrores do sistema prisional brasileiro (Zaluar, 1996a, p. 102).

Bauman diz : "nossa sociedade é uma sociedade de consumo" (1999, p. 87), e ele não quer dizer, com isso, que, na sociedade em que vivemos, todos os seus membros consomem, pois isso é óbvio. $\bigcirc$ que pretende é apontar para o fato de que a sociedade que nos precedeu, ou seja, a sociedade moderna, nas suas camadas fundadoras, era constituída de "produtores e soldados". Hoje, temse pouca necessidade de mão-de-obra industrial em massa e de exércitos recrutados; em vez disso, o de que se precisa na sociedade neste estágio pós-moderno é do engajamento dos seus membros pela condição de consumidores.

Embora pareça não haver grande diferença entre os dois estágios da sociedade citados, podemos dizer que tal diferença se faz imponente em aspectos da vida cultural e individual. Na sociedade de consumo:

[...] nada deveria ser abraçado com força por um consumidor, nada deveria exigir um compromisso "até que a morte nos separe", nenhuma necessidade deveria ser vista como inteiramente satisfeita, nenhum desejo como último [...] O que realmente conta é apenas a volatilidade, a temporalidade interna de todos os compromissos; isso conta mais que o próprio compromisso, que, de qualquer forma, não se permite ultrapassar o tempo necessário para o consumo do objeto de desejo (Bauman, 1999, p. 89).

De outro modo, mas também enfocando a supremacia da individualidade na sociedade moderna, Peralva (1996) compreende o envolvimento do jovem em atividades violentas como engajamento em um risco de morte. Enfatizando a liquidação de formas antigas de regulação das relações humanas através da abstração da sociedade de sua função protetora do indivíduo, e apontando a mutação cultural que subtraiu a preeminência do adulto sobre o jovem, 
a autora credita o engajamento na violência a uma forma de gestão da angústia da morte (noção desenvolvida por Morin, 1997).

Segundo Peralva (1996), a sociedade brasileira desamparou os indivíduos nas últimas duas décadas, por efeito de três mecanismos: processo de transição democrática sem a criação de instrumentos capazes de assegurar o funcionamento de um Estado de direito (com aparelhos policial e judiciário modernos, eficazes e não violentos); crise do sindicalismo e dos movimentos populares urbanos, e agravamento do processo de priorização da individualidade, em detrimento das categorias coletivas de organização da experiência social, que se deu por meio da rápida modernização da sociedade brasileira, com a elevação dos padrões de consumo e a alteração de padrões culturais, induzida pelos meios de comunicação de massa.

Nos estudos anteriormente mencionados, percebe-se uma preocupação com a afirmação da individualidade, nas sociedades contemporâneas, deflagrada pela desestruturação das redes de relações sociais estáveis que impunham o limite da liberdade individual através da sensibilidade ao outro.

Pode-se fazer um paralelo, como o fez Peralva (1996), da violência que provoca a morte, mas que também traz a seus agentes o risco de morte, com a angústia da morte. Morin (1997), introduzindo entre o homem e outros animais mais uma diferenciação, fala da consciência da morte como algo traumático para a individualidade humana, e, ao mesmo tempo, constituinte dessa individualidade ímpar.

É pelo fato de existir, na humanidade, sentimento de individualidade (a consciência de ser único em meio a outros semelhantes) que a inteligência da espécie, como protetora contra a ameaça da morte, fica subtraída em relação ao saber oriundo da experiência. Dessa forma, como o homem apreende a morte a partir de sua experiência durante a vida, e não pelo saber da espécie, Morin (1997) afirma que há uma promoção da individualidade em relação à espécie. Portanto, sem o saber inato, o homem se vê obrigado a aprender e reaprender a morte o tempo todo, e, na medida em que afeta a sua individualidade de forma traumática, já que representa exatamente a sua perda, tenta negá-la, elaborando o mito da imortalidade com rituais fúnebres e similares.

A supremacia da individualidade no homem, que desencadeia uma angústia de morte, segundo Morin (1997), pode ser dissolvida através da afirmação do grupo social no íntimo do indivíduo; a sociedade deveria, então, desempenhar o papel abstraído da espécie, que seria o de proteger seus indivíduos do horror à morte.

Poder-se-ia dizer que o sentimento que o indivíduo possui de sua própria existência envolve o de uma simbiose com os outros membros do grupo, contanto que não se entenda isto como uma existência em comum do tipo dos animais inferiores que vivem em colônias, mas apenas existências que se sentem numa dependência inevitável, constante e recíproca, a qual, aliás, em tempo normal, não é formalmente sentida, exatamente porque está constantemente presente, como a pressão atmosférica. [...] A participação do indivíduo no corpo social é um dado imediato contido no sentimento que ele possui de sua própria existência (Lévy-Bruhl, Carnets, citado por Morin, 1997, p. 39).

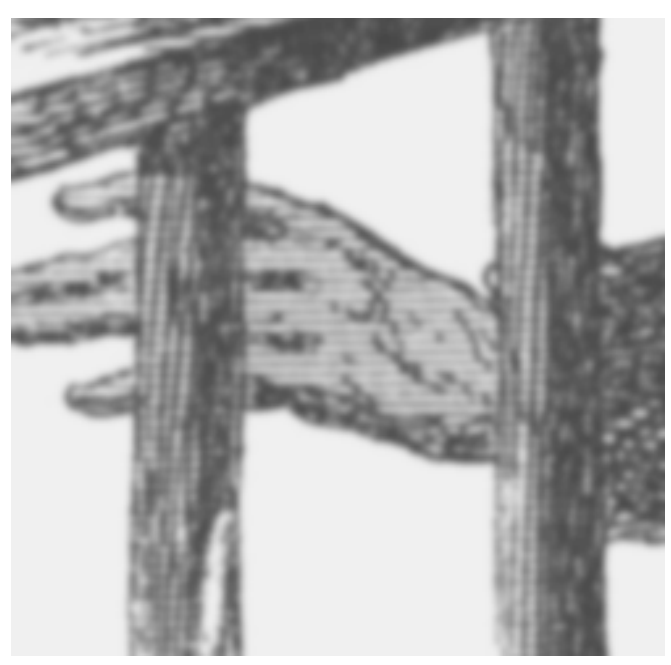

A primazia da individualidade sobre o grupo social faz surgirem, de novo, as angústias de morte. É nesse sentido que Peralva (1996) toca na questão do recuo da sociedade, que acaba por deixar os indivíduos desamparados frente à angústia de morte, quando, por exemplo, não assegura a eles seus direitos civis e seus direitos humanos.

Assim, a carência de um sentimento de coletividade, as injustiças sociais, a ineficiência e a perversão dos aparelhos de controle social, na sociedade brasileira, fadam o indivíduo a relações sociais mediadas pela violência, impossibilitam a conquista de padrões mínimos de paz social e, por que não, a consolidação dos direitos humanos, ambos requisitos básicos para a instauração do regime democrático (Machado e Marques, 1993; Adorno, 2000).

As considerações de natureza evolutiva apresentadas acima não podem, de forma alguma, 
ser confundidas com a idéia de defesa de algum tipo de determinação biológica da criminalidade. É importante frisar essa questão, uma vez que a adesão a tal tipo de determinismo nunca desapareceu completamente, estando sempre de volta com nova roupagem. Já se propôs que a criminalidade podia ser prevista a partir de certos traços faciais. Mais tarde, a possibilidade de um cromossomo $\mathrm{Y}$ extra explicar a criminalidade exerceu grande fascínio sobre alguns estudiosos. Mais recentemente, fica evidente a ascensão do determinismo neurogenético, que busca genes que possam explicar a presença de certas estruturas corporais pretensamente justificadoras das mais diversas modalidades de ação. Além de deixar claro que tais "teorias" ignoram o avanço do conhecimento na genética e nas neurociências, Rose (1997) destaca que

há muitas e óbvias objeções a tal suposição. Algumas indicam que essas discussões sempre parecem focalizar o crime na classe trabalhadora: ninguém estuda a hereditariedade da tendência a cometer fraudes nos negócios, ou os fatores bioquímicos pertinentes em homens de classe média que espancam suas esposas. Outras objeções denunciam a complexa e às vezes contraditória teia de significados que envolve o próprio conceito de violência (p. 21),

ou o conceito de criminalidade, acrescentamos.

Parece-nos essencial ressaltar que, nas mais diversas sociedades caracterizadas pela desigualdade, existe absoluto predomínio de crimes contra a propriedade, e esse fato pode ser adequadamente compreendido como tentativa normal e consciente de adquirir propriedade. Taylor, Walton e Young (1980) propõem que "uma sociedade que está predicada sobre direito desigual de acumulação de propriedade dá origem a desejos legais e ilegais de acumular propriedades tão rapidamente quanto possível" (p. 40).

\section{O Sistema Carcerário}

Nos meios de comunicação, a penitenciária tem sido alvo de constantes discussões nos últimos anos, sobretudo no tocante à superpopulação e à ineficiência, que se apresentam como problemas aparentemente insolúveis, tal sua longevidade. A indignação jornalística e popular freqüentemente gira em torno das rebeliões e das fugas, ocasiões nas quais sempre se discute o absurdo número de criminosos distribuído no sistema carcerário brasileiro. A violência nos presídios é, hoje, muito visível e percebida como problema social. população o risco ao qual está sujeita, emanado da instituição prisional, uma vez que ela não cumpre eficazmente seu desejado papel de formar um cordão de isolamento em torno das "anomalias" sociais. Em consonância, o que se espera das autoridades responsáveis é que implementem um conjunto de estabelecimentos carcerários com dispositivos físicos, materiais e recursos humanos suficientes para calar ou tornar invisível a massa carcerária, e isso deve ser feito consumindo o mínimo possível de verba pública. Tal perspectiva foi apresentada por Thompson (1976), quando afirma que o fato de um expresidiário tornar a cometer atos criminosos é, em geral, visto com naturalidade, pois, da prisão, exigese, apenas, que mantenha seus internos longe da sociedade. Acrescentaríamos que o fato mencionado talvez seja visto até com certa satisfação, já que reforça a percepção compartilhada por muitas pessoas de que nada há a fazer com "bandidos" a não ser mantê-los trancafiados (sem muita preocupação com as condições em que o encarceramento se dará) ou exterminá-los.

Situando historicamente a pena de privação de liberdade, configuramos a problemática da instituição carcerária, emergente no contexto atual, como questão social, política e econômica.

Por hipótese, em sociedades mais igualitárias em termos de oportunidades e de exercício da cidadania, e também mais pluralistas em termos culturais, não só a taxa de crimes contra a propriedade (e, em decorrência, de crimes contra a pessoa) deveria ser reduzida, mas também a perspectiva de recuperação e reintegração via mecanismos legais (não necessariamente, a prisão) deveria ser mais eficiente, pela maior proximidade (psicológica, talvez) para o infrator de um novo e atingível alvo: a vida em sociedade com oportunidades reais, com possibilidades não degradantes de trabalho, com cidadania respeitada. Em condições sociais de acentuada iniqüidade, como no Brasil atual, as condições das prisões, em combinação com as condições sociais vigentes na sociedade à qual o preso deveria reintegrar-se, não sinalizam qualquer probabilidade razoável de que seja possível ou vantajosa tal reintegração (para muitos, apenas submissão, apenas "abaixar a crista"). Em outras palavras, para o detento brasileiro, não há prognóstico, há apenas diagnóstico: bandido.

\section{A população carcerária}

Ao tomarmos como foco de atenção as pessoas que vivem nas instituições carcerárias, podemos observar mais um aspecto importante desse sistema inserido na sociedade, e que concretiza, de forma dura, a violência do sistema socioeconômico 
contra a maioria da população do País. Já no relatório oficial do IX Congresso Internacional da Defesa Social ocorrido em Caracas (Fragoso, 1977), aparece no tópico "Marginalidade e Delinqüência" a conclusão fatídica de que, na América Latina, apenas as pessoas das classes de baixa renda sofrem a ação do Direito Penal, por meio do aparato policial-judiciário, enchendo as prisões e produzindo o estereótipo de criminoso primordialmente como sendo o de habitante de bairros empobrecidos. Fragoso menciona ainda que o Direito, assim como qualquer outro mecanismo de controle social, é governado por preconceitos e estereótipos socialmente condicionados, concepção essa corroborada por Thompson (1983). Portanto, há uma seleção daqueles sobre os quais recairá a aplicação do Direito Penal, não constituindo a população carcerária uma amostra representativa do conjunto total de infratores.

A identificação de criminoso e marginal resulta do fato de serem atingidos pela justiça substancialmente os pobres e desfavorecidos, que enchem as prisões e que constituem a clientela do sistema. [...] A experiência demonstra que as classes sociais mais favorecidas são praticamente imunes à repressão penal, livrando-se com facilidade, em todos os níveis, inclusive pela corrupção (Fragoso, 1977 , p. 03).

É ainda mais fácil compreender a impunidade de pessoas de classe de renda alta quando levada em consideração a organização histórica da vida social brasileira, analisada por DaMatta (1997) através do rito do "sabe com quem está falando?". Este representa a preocupação do sistema social com o "cada qual no seu lugar", ou seja, simboliza uma forma de interação balizada pela hierarquia e pela autoridade que reproduz "a visão de mundo como feito de categorias exclusivas, colocadas numa escala de respeitos e deferências" (DaMatta, 1997, p. 186). Desse modo, o "sabe com quem está falando?" é utilizado no cotidiano para diferenciar as pessoas quanto à posição social. Os agentes da Justiça são parte dessa sociedade, e acabam, na sua atuação, por reproduzir, com freqüência, esse traço da vida social brasileira.

\section{A organização social da prisão}

Sobre a organização social dos presídios, pode-se concluir que está pautada em relações sociais limítrofes de seres humanos submetidos a um regime de controle. Embora haja normas e hierarquia prescritas formalmente, a disposição de papéis e a organização interna das prisões fogem à ordem oficial (Thompson, 1976; Coelho, 1987; Castro, 1991). Thompson (1976) acredita que a interação entre esses dois modos de vida (o oficial e o interno-informal) gera o surgimento de conflitos, os quais requerem um processo de acomodação constante dos participantes da sociedade prisional nas relações entre si.

Castro (1991) demonstra como a violência medeia as relações no interior das penitenciárias:

Menos conhecidas são as formas sutis de violência, constitutivas mesmo da rede de relações sociais que atravessa sujeitos posicionados de modo diferente na estrutura social da prisão. [...] Referemse a mecanismos, estratégias, táticas, tanto de controle da massa carcerária por parte da equipe dirigente, quanto de construção de experiência: a de dominação e sujeição daqueles que vivem sob tutela e abrigo da prisão. [...] aqueles (mecanismos, estratégias, táticas) estão profusamente presentes no interior do universo simbólico, compartilhado de modo ambivalente por dirigentes e seus subordinados (Castro,1991, p. 57).

Assim, todos os participantes da sociedade interna da prisão, desde os condenados até a equipe dirigente, visto que estão em relação constante uns com os outros, sofrem os efeitos da prisonização (noção cunhada por Clemmer, citado por Thompson, 1976, p. 52), adotando os valores que vigoram intramuros.

Nesse sentido, vale a pena fazer menção a um curioso trabalho, que teve grande repercussão nos meios de comunicação e que, muitos anos depois, continua gerando controvérsias, tendo sido objeto, décadas depois, de um documentário do qual participaram os protagonistas originais da pesquisa. Trata-se do trabalho de Haney, Banks e Zimbardo (1973), no qual foi montada uma experiência de "prisão simulada" com estudantes universitários, voluntários, remunerados, selecionados quanto à estabilidade emocional, de classe média, estranhos entre si e que foram aleatoriamente designados para servir como guardas ou detentos. Em uma situação que reproduzia fisicamente uma pequena prisão, a experiência foi conduzida, com duração programada de duas semanas. Os estudantes designados para servirem como presos receberam contratos garantindo-lhes alimentação adequada, roupa, alojamento e assistência médica, e ficaram sabendo que perderiam alguns dos seus direitos civis e que não haveria maus tratos físicos de qualquer espécie. Aos estudantes designados para servirem como guardas, foi dito que o objetivo do experimento era estudar o comportamento dos detentos e que eles deveriam manter um grau razoável de ordem na "prisão", sem fazer uso de violência. Os "guardas" recebiam uniformes e cassetetes e os "presos" apenas uma roupa semelhante a um camisolão.

\section{A identificação de criminoso e marginal resulta do fato de serem atingidos pela justiça substancialmente os pobrese desfavorecidos, que enchem as prisões e que constituem a clientela do sistema. [...]A experiência demonstra que as classes sociais mais fovorecidas são praticamente imunes à repressão penal, I'vrando-se com facilidade, em todos os níveis, inclusive pela corrupção}

Fragoso 
Embora planejada para durar catorze dias, a experiência durou apenas seis dias, em função da extrema depressão e ansiedade dos "detentos". Testemunhou-se a transformação de alguns dos estudantes norte-americanos comuns em "guardas" hostis, que rapidamente redefiniram os direitos dos presos (por exemplo, alimentação e sono) como privilégios submetidos à retirada. De forma similar, outros estudantes transformaram-se em detentos autodepreciativos (supostamente, em função do regulamento arbitrário e da perda de identidade pessoal), que se colocavam ao lado dos guardas contra outros detentos que "criavam problemas". Mesmo encarados com toda a precaução que esse tipo de trabalho exige, os resultados parecem apontar indícios de um tipo de influência que, supostamente, seria mais concreta nas prisões reais (já que, nessa experiência de simulação, não aconteceram eventos da gravidade de espancamentos por parte dos guardas nem atividade sexual forçada, por exemplo).

objetivo principal das administrações de presídios tem sido sempre o controle dos internos. Porém, isso tradicionalmente tem sido conseguido, como vimos, não somente pela força, mas também

fazendo vista grossa a algumas infrações, tais como tráfico de drogas e preparo de bebidas alcoólicas, em troca de manutenção da ordem global. Com efeito, a prisão consegue a ordem tolerando a desordem. Esta contradição cria uma situação na qual as indulgências passam a ser vistas, eventualmente, como tolerantes demais ( $p$. 503),

com conseqüências desastrosas para a estrutura social da prisão.
Apesar das limitações desse tipo de caracterização dos diversos membros da população carcerária que fizemos até aqui, julgamos que ela seja útil no como um sistema social.

Thompson (1976) descreve o sistema social da prisão destacando os guardas como possuidores de uma tradição de comportamentos adotados dentro da instituição, já que são profissionais fixos do quadro de pessoal (em contraposição ao diretor). São eles que vão lidar diariamente com os internos e manter a segurança e a ordem, o que os põe numa situação de tensão, mediando os dois conjuntos de regras (formal e informal). Para tanto, o guarda disporá do seu poder de influir na distribuição das punições e recompensas previstas no regulamento ou "dispostas" nas normas informais.

Rios (1998), reconhecendo que, por mais severo que seja o regime carcerário, sempre existe o sistema de barganha, de troca de concessões entre presos e funcionários, chega a dizer que "às vezes, do sistema, mas tudo indica que o funcionamento sem percalços dessa rede informal de relações é que evita os distúrbios" (p. 10). Por mais triste que seja, é forçoso reconhecer que esse é também o retrato do Brasil que está do lado de fora da prisão, no qual muitas coisas se ajeitam não em função de respeito a direitos, mas em função de troca de favores e acesso a privilégios.

Referindo-se às condições carcerárias norteamericanas, Eitzen e Timmer (1985) destacam essa mesma constatação. Dizem eles: sentido de evidenciar o estabelecimento prisional essa relação confunde-se com a própria corrupção o objetivo principal das administrações de presídios tem sido sempre o controle dos internos. Porém, isso tradicionalmente tem sido conseguido, como vimos, não somente pela força, mas também fazendo vista grossa a algumas infrações, tais como tráfico de drogas e preparo de bebidas alcoólicas, em troca de manutenção da ordem global. Com efeito, a prisão consegue a ordem tolerando a desordem. Esta contradição cria uma situação na qual as indulgências passam a ser vistas, eventualmente, como tolerantes demais (p. 503), com conseqüências desastrosas para a estrutura social da prisão.

Em relatório sobre tortura no Brasil (Organização das Nações Unidas, ONU, 2001), confeccionado pelo relator especial da Comissão de Direitos Humanos da ONU, consta a informação, fornecida por delegados e diretores de presídios, que a situação de superlotação e a carência de recursos humanos produziam uma grande tensão entre o pessoal de segurança e a população carcerária, tensão essa que se reverte, por vezes, em tentativas de fuga e rebeliões. Assim, a necessidade de o pessoal de segurança manter a ordem nos estabelecimentos justificaria o duro tratamento (reconhecido pelo relator como tortura ou maus tratos) ao qual os detentos estariam submetidos (tópico 12 do relatório).

O diretor possui um poder bastante limitado na prisão, pois, logo ao assumir a função, percebe a existência de uma organização não-oficial em pleno vigor, sobre a qual não pode ter muito controle. Mesmo que o diretor tenha um projeto de administração anterior, deverá rever seus anseios de modo a adaptar-se ao sistema, com o objetivo de evitar as fugas e manter a ordem interna. Esse fim informal, que passou a ser o principal das direções, submetidas que estão ao equilíbrio das relações entre os guardas e os internos, é levado a cabo quando o diretor se prisonifica (Thompson, 1976), passando a ser integrante do jogo de relações prisionais.

O sistema social da instituição penal encarregarse-á de incluir o apenado, desde a sua chegada, na mais baixa posição social. O prisioneiro empenhar-se-á em escolher estratégias de sobrevivência (Castro, 1991) e, na maior parte das vezes, aceitará um papel inferior e procurará, ao máximo, equilibrar-se entre o código formal e o informal, buscando as vantagens e evitando as punições que pode receber (Thompson, 1976).

Passado o aprendizado inicial de entrada na instituição, o preso procurará, ao máximo, voltar à vida, mesmo havendo a impressão de que, no tempo da pena, é como se ele estivesse em banhomaria, apagado, "morto". A organização prisional 
está disposta de tal forma que propicia uma disputa entre os presos, incentivando-os a comportamentos individualistas e egoístas, os quais são benquistos pela equipe dirigente. Enquanto esses comportamentos são mantidos, o controle sobre a massa carcerária é maior, pois impedem "uma tomada de consciência político-social" (segundo Accattatis, 1977, citado por Menandro, 1984, p.75), dificultam revoltas coletivas e facilitam a ciência de qualquer plano de fuga em elaboração (através dos alcagüetes).

Tal característica de reação ao encarceramento parece ser geral, não se limitando às condições brasileiras. O que existe são amplas diferenças individuais nas reações ao encarceramento. Algumas pessoas reagem ao encarceramento com distúrbios emocionais ou mentais severos, mas essa não é uma regra geral. Citando dados obtidos no Canadá, em 1988, e nos Estados Unidos, em 1989, Bartol (1991) revela que muitos internos apresentam sinais de depressão durante a fase inicial de suas sentenças. Essa reação danosa não é surpreendente, uma vez que a prisão implica dramática ruptura nas atividades cotidianas, envolvendo restrições, privações e constrangimentos. Entretanto, acrescenta o citado autor, tais reações iniciais logo se dissipam para muitos detentos, não sendo possível discernir distúrbios emocionais duradouros após o detento adaptar-se à rotina da prisão. Além disso, complementa Bartol, os dados mostram que a idade do detento correlaciona-se, consistentemente, com violações das normas da prisão, com os detentos mais jovens mostrando-se mais propensos a engajarem-se em episódios classificados como de má conduta em comparação com os mais velhos. $\mathrm{O}$ autor adverte que existem duas condições especiais em que tais considerações perdem sumariamente sua validade: quando existe superlotação carcerária ou quando existe a prática de isolamento. Não está dito, mas acrescentaríamos uma terceira condição especial: quando existe tortura ou outras modalidades de punição física.

Tais processos não impedem que comportamentos violentos entre os presos sejam comuns, passando mesmo a fazer parte da instituição. No relatório "O Brasil Atrás das Grades" (Human Rights Watch, HRW, ca. 1998), de uma organização nãogovernamental estrangeira, a violência entre os presos é descrita como determinada por vários fatores conjugados: as péssimas condições das prisões, a falta de supervisão eficiente, a abundância de armas e a ausência de classificação de presos.

Coelho (1987) descreve detalhadamente o aprendizado e a trajetória do preso na instituição prisional. O preso precisa, além de aprender as normas e os códigos da penitenciária, tornar-se membro competente de uma sociedade sui generis, na qual a violência modula as relações.

É um duro e perigoso aprendizado, ao fim do qual o indivíduo terá perdido sua "identidade" anterior. É um processo de transformação que cria uma segunda prisão: o interno torna-se cativo da "sociedade dos cativos", totalmente dependente dela para sobreviver. Não é por outra razão que o objetivo de recuperar o preso começa a falhar do momento em que ele penetra num xadrez de delegacia policial (Coelho, 1987, p. 63).

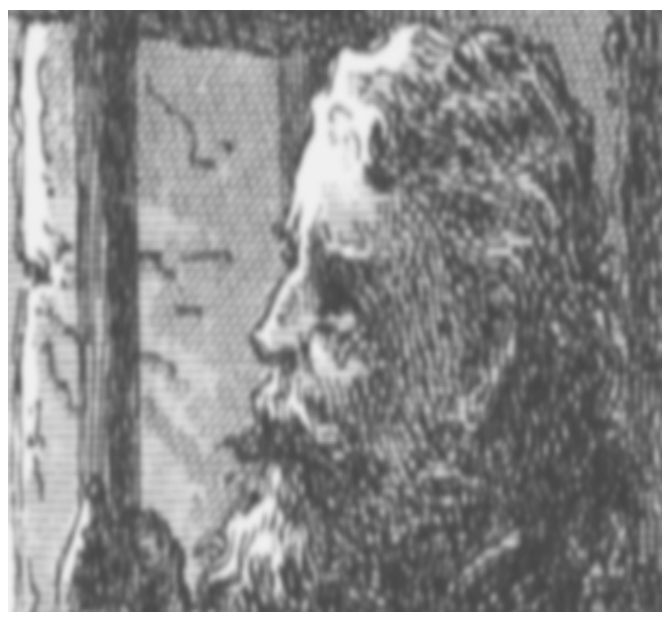

Nesse sentido, o calouro da instituição prisional passaria por um processo de mortificação do eu (Goffman, 1990, p. 24), com a perda das disposições gerais do mundo externo (a forma como estava habituado a agir, a apresentar-se aos outros) e, principalmente, com a perda da sua integridade física e segurança pessoal. Porém, considerando as condições brasileiras, questionamos a afirmação de Goffman (1990), em trabalho a respeito das instituições totais, de que o condenado passa a fazer parte de uma sociedade que em nada se parece com o mundo externo. No caso brasileiro, parece haver uma adaptação prévia dos indivíduos das classes populares das periferias urbanas à instituição prisional, como pôde ser observado anteriormente. Além de serem "recrutados", freqüentemente, pelo aparato policial-judiciário para habitar as cadeias, convivem diariamente com violações dos direitos civis e sociais comuns nos países em desenvolvimento.

Pode-se pensar que a entrada na prisão piora a situação do indivíduo, pois ele carregará, além dos problemas inerentes à condição de pobreza, o estigma de criminoso, o que dificulta ainda mais sua inserção no mercado de trabalho e na vida 
social plena e aumenta a chance de tornar-se alvo de vigilância discriminatória de policiais.

Ramalho (1979), em estudo com presidiários, ressalta que

para a polícia, a pessoa que passou pela prisão pertence ao crime definitivamente. Segundo os presos, a perseguição policial aos ex-presos é comum e é considerada como um dos principais motivos para o aumento da reincidência (p. 119, itálicos no original).

É de se imaginar que o apenado vê-se aprisionado por uma malha invisível de relações de poder, da qual não pode fugir e que não cessa mesmo quando a pena já foi cumprida.

"...para a polícia, a pessoa que passou pela prisão pertence ao crime definitivamente. Segundo os presos, a perseguição policial aos ex-presos é comumeé considerada como um dos principais motivos para o aumento da reincidência."
Depois do panorama exposto até aqui, podemos presumir que a organização social prisional se encontra em harmonia precária todo o tempo, visto que: 1) baseia-se num sistema de poder; 2) a vida nos presídios é incerta e insegura e que 3) a instituição prisional funciona como instrumento de marginalização e reprodução da delinqüência.

Assim, as instituições de execução penal corrompem e despreparam os indivíduos para a vida livre, além de não operarem como instrumento intimidativo de crimes. O que proporcionam, de fato, é o castigo, cujo preço torna-se tão alto a ponto de converter-se em eterno, já que, uma vez alvo da sanção penal, o condenado estará sempre pronto a pagar mais penitências. Aí estão os motivos pelos quais a própria clientela (segundo Castro, 1991, p.57) denomina a prisão de "universidade do crime".

\section{Sistema social $\mathrm{X}$ sistema legal}

As leis brasileiras de execução penal são peças retóricas (Coelho, 1987; Herkenhoff, 1987; Adorno, 1991; Castro, 1991; Sarubbi e Rezende, 1997). Não há, nos estabelecimentos penais, devido à precariedade do sistema, condições mínimas que assegurem ao condenado direito à assistência material, à saúde, jurídica, educacional, social, ou, ainda, condições que garantam o cumprimento do dever de trabalhar do condenado. Não há sequer Comissão Técnica de Classificação ou mesmo aquela fiscalização precisa e rigorosa da instituição e das penas dos presidiários que deveria ser realizada pelo Juiz da Execução, pelo Ministério Público e pelo Conselho Penitenciário. É interessante como a Lei de Execução Penal (Brasil, 1984) designa várias instâncias para supervisionar os estabelecimentos e serviços penais, parecendo prever a dificuldade pena de privação de liberdade já demonstrou não

poder ser solucionado pela lei, pois ela não condiz com a realidade social, política e econômica.

A idéia de preso reproduzida pela mídia e pelo senso comum não comporta o sistema prisional previsto pela lei, haja vista o estudo realizado por Caldeira (1991), em São Paulo, que demonstra a vinculação da noção de direitos humanos a "regalias para bandidos", encerrando uma opinião pública contrária aos direitos humanos. Além disso, pode-se acrescentar que, num país em que há uma alta taxa de exploração, é necessário que a situação da prisão seja muito pior que a situação dos simples desfavorecidos, isto é, "é preciso que a prisão seja terrível para que ninguém queira ir para lá" (Pinheiro, 1985, p. 67). Se a opinião pública é contrária a "benefícios" para presos, não se poderia esperar que passasse pelo interesse dos agentes políticos governamentais implantar o sistema previsto pela lei, cujo custo é elevadíssimo. Desse modo, é politicamente improvável a mudança na instituição penal, a não ser que se transforme toda uma forma de pensar o condenado e a pena, assim como as relações sociais e o crime.

O relatório sobre tortura no Brasil, produzido pelo relator especial da Comissão de Direitos Humanos da ONU (ONU, 2001), e o relatório "O Brasil Atrás das Grades", da Human Rights Watch (HRW, ca. 1998), descrevem violações graves aos direitos humanos sofridas pela população dos estabelecimentos penais no País.

O relator especial da Comissão de Direitos Humanos da ONU, em visita a estabelecimentos prisionais de São Paulo, Rio de Janeiro, Minas Gerais, Pernambuco e Pará, descreveu que o principal problema encontrado nas instituições, à exceção do presídio Nelson Hungria, em Minas Gerais, foi a situação de superlotação, que, somada a uma arquitetura inadequada, com péssimas instalações, falta de higiene e saneamento, falta de serviço de saúde e precária qualidade ou até mesmo escassez de alimentos, tornam subumanas as condições de detenção (tópico 11). O relator acrescentou que essas condições não podem ser atribuídas simplesmente à falta de recursos financeiros, mas, também, à conseqüência de políticas deliberadas ou de uma grave negligência por parte das autoridades competentes (tópico 11). A constatação de violação dos direitos inerentes à condição humana nos cárceres inspecionados por parte do relator especial da Comissão de Direitos Humanos da ONU, em especial, de tortura e maus tratos, provocou a deliberação de um rol de 30 recomendações, entre elas:

Qualquer pessoa presa deveria ser informada de seu direito contínuo de consultar-se, em 
particular, com um advogado, a qualquer momento, e de receber assessoramento legal e gratuito. Uma declaração dos direitos dos detentos, tal como a LEP, deveria estar prontamente disponível em todos os lugares de detenção, para fins de consulta pelas pessoas detidas e pelo público em geral (tópico 5, recomendações).

As queixas de maus tratos deveriam ser investigadas com rapidez e diligência. O resultado não deveria depender unicamente de provas referentes ao caso individual, mas de investigações acerca de padrões de maus tratos. As pessoas envolvidas deveriam ser suspensas de suas atribuições enquanto se processa a investigação. Os culpados deveriam ser punidos com a demissão, medida que envolverá purgação radical de alguns serviços (tópico 10, recomendações).

Há necessidade de um programa de conscientização no âmbito do Judiciário no tocante à superlotação crônica do sistema carcerário. $\bigcirc$ Judiciário deveria assumir alguma responsabilidade pelas condições e pelo tratamento a que ficam sujeitas as pessoas que condena ou que estão sob detenção préjulgamento (tópico 15, recomendações).

A assustadora situação de superlotação em alguns estabelecimentos precisa acabar imediatamente; se necessário, mediante ação do Executivo, exercendo clemência, por exemplo, com relação a transgressores primários, não violentos ou suspeitos de transgressão (tópico 23, recomendações).

O relatório da HRW (ca. 1998) sobre o sistema carcerário brasileiro é vasto e rico de detalhes. Produzido a partir de visitas a instituições e entrevistas diretas com presidiários, autoridades e agentes penitenciários, o relatório está dividido em nove pontos centrais: a superlotação, as delegacias policiais como prisões, as condições físicas, a assistência, os abusos entre presos, os abusos cometidos por policiais, o contato com o mundo externo, o trabalho e a vida das detentas. A pesquisa ocorreu entre setembro de 1997 e abril de 1998, e foram visitados cerca de 40 presídios, cadeias e delegacias de polícia.

Além do já conhecido problema de superlotação no sistema carcerário brasileiro, a HRW (ca. 1998) descreveu, inclusive com transcrições de entrevistas com presos e reféns de rebeliões, práticas de torturas e de brutalidades letais cometidas por agentes carcerários, policiais civis, policiais militares e até mesmo por diretores de instituições prisionais. As práticas de tortura comumente ocorrem nas delegacias policiais e nas celas de punição dos estabelecimentos carcerários. Tão trágicos quanto as torturas, são os assassinatos cometidos pela polícia militar quando das ações realizadas nas tentativas frustradas de fuga que se transformaram em rebeliões, em João Pessoa (julho de 1997, Presídio do Róger), Fortaleza (dezembro de 1997, Instituto Penal Paulo Sarasate) e Natal (fevereiro de 1998, Penitenciária Central João Chaves), relatadas no relatório da HRW.

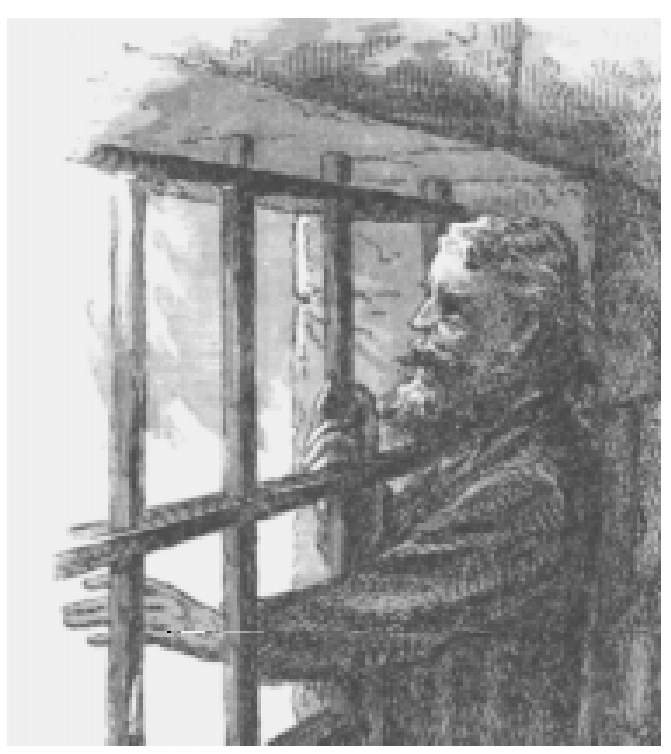

A detecção, no estudo da HRW (ca. 1998), de que as exigências da LEP com relação à progressão de penas não têm sido postas em prática, endossa a lista de agravantes para a superlotação e para a violência nos presídios. Normalmente, um preso que inicia a pena no regime fechado, após cumprir parte dela, deveria ser transferido para um estabelecimento de regime semi-aberto e, consecutivamente, para outro de regime aberto até o seu retorno à sociedade. No relatório "O Brasil Atrás das Grades", consta uma estimativa do Ministério da Justiça, de maio de 1998, de que 11,2\% (cerca de 11.000 detentos) dos presos condenados no País estavam qualificados para a progressão da pena, embora poucos estivessem se beneficiando disso.

Para a HRW, as causas do fracasso da progressão da pena repousam sobre a escassez de assistência jurídica, a escassez de juízes para processar seus casos e, ainda, sobre o pequeno número de estabelecimentos de regimes abertos ou semiabertos (fato compatível com os dados do Departamento Penitenciário Nacional, DEPEN, de 2000).

\section{Rebeliões em prisões brasileiras}

Há um fenômeno que se coloca hoje como um grande denunciador do embaraçoso sistema 
carcerário brasileiro: as rebeliões. Estas acontecem, atualmente, como denunciadoras de uma organização social insustentável e revelam, ainda, a fragilidade das políticas públicas relativas à administração carcerária.

Como ilustração comparativa, mencionamos o registro de Eitzen e Timmer (1985) de que rebeliões violentas de prisioneiros contra as autoridades penitenciárias foram numerosas no decorrer da história norte-americana. Sabe-se que ocorreram, no mínimo, 400 levantes em prisões, entre 1855 e 1955. Tais levantes foram espontâneos, em alguns casos, e organizados, em outros, e suas causas foram variadas. Quase sempre, os motins aconteceram visando a dramatizar as demandas dos prisioneiros por transformações nas condições em que estavam: melhores alimentação e assistência médica, melhores condições de recreação/lazer, trabalho produtivo, redução da superlotação, melhoria nas condições sanitárias, oportunidades educacionais mais acessíveis, restabelecimento de direitos humanos básicos e tratamento mais humano por parte dos guardas. Os autores destacam, ainda, que, nos anos 60 e 70, como reflexo da aumentada atividade política de grupos socialmente discriminados na sociedade norteamericana, muitos dos incidentes prisionais passaram a ocorrer também com a característica de contestação política às evidências de superrepresentação de algumas minorias entre os detentos (com destaque especial para a questão racial).

Voltando ao Brasil, não podemos deixar de evocar o marcante episódio ocorrido em outubro de 1992, na Casa de Detenção de São Paulo (hoje desativada), conhecido como o massacre do Carandiru. Em tal ocasião, foram exterminados, por policiais militares, 111 presos (mais 110 ficaram feridos) que haviam promovido uma rebelião iniciada com um ajuste de contas entre dois detentos (Machado e Marques, 1993; Varella, 1999). Segundo dados obtidos por Machado e Marques (1993), nenhuma negociação foi estabelecida e a ação da polícia foi gravemente errônea e desastrosa. Em vez de garantir a segurança dos presos em conflito e o fim do combate (não havia reféns), a polícia entrou no Pavilhão 9 fortemente armada e deu fim a todos os que por lá encontrou, inclusive utilizando-se de pitadas de perversidade, pois continuou a assassinar pessoas mesmo depois que o tumulto havia sido apagado e os cadáveres estavam sendo carregados para o pátio externo da penitenciária (Machado e Marques, 1993).

Pinheiro (1985), sete anos antes do nefasto acontecimento, chamava a atenção para a maneira como a polícia militar atuava em relação às rebeliões de presos, obstruindo as possibilidades de negociações:

Rebeliões transformadas em novos motins, por motivos aparentemente fúteis, no sentido de que uma negociação se poderia estabelecer e o Estado deveria estar sendo capaz de atender a essas reivindicações, sem uso da força armada. Essas polícias militares atuam na função de castigo extra, como uma condenação suplementar à condenação que já grava sobre os detentos (Pinheiro, 1985, p. 69).

Em pesquisa realizada com noticiário jornalístico sobre rebeliões, no Brasil, Tavares (2001) observou, através da análise de 195 ocorrências, que as rebeliões caracterizam-se por tentativas (desesperadas, e, às vezes, contraproducentes) de modificações das condições insuportáveis de:

superlotação carcerária;

alimentação precária e de má qualidade;

maus tratos, torturas (envolvendo tanto funcionários quanto "detentos chefões") e isolamentos;

] riscos à saúde;

aumento do "custo" pessoal das exigências impostas pela corrupção no sistema carcerário;

desmandos da direção;

descontrole quanto ao andamento do cumprimento das penas;

$\square$ inexistência ou insuficiência de programas de recuperação para novas oportunidades de convivência e adaptação social;

abusos e manipulações em torno do controle das visitas de parentes e amigos.

Os dados mostraram, com clareza, que as rebeliões não têm acarretado mudanças estruturais objetivas no sistema carcerário. Grande parte das rebeliões ou têm como reivindicação a transferência de presos para outros estabelecimentos prisionais ou acabam em transferências. Estas promovem um rodízio de presos pelo sistema carcerário que modifica apenas circunstancialmente a organização social da prisão. A forma como está firmada e disposta a instituição carcerária brasileira continua a mesma após as rebeliões, na medida em que está sempre pronta para novas rebeliões, promovidas por outros presos da unidade ou por presos provenientes (por transferências) de outros estabelecimentos.

Como a transferência é uma das poucas reivindicações que podem ser negociadas com o governo (Marques, 1999), sendo, muitas vezes, uma necessidade gerada pelo próprio andamento da rebelião (ILANUD, 1998), ela parece fazer parte do sistema penitenciário quase como um "direito adquirido" mal regulamentado. Como Tavares 
(2001) mostrou na citada pesquisa, a freqüência de transferências como conseqüências de incidentes prisionais é exorbitante, especialmente no Estado de São Paulo. Antes, alternativa do governo para as negociações, hoje, institucionalizada como saída estratégica para os rebelados e diretores de prisões, a transferência parece servir como forma de ter acesso a:I

presídios em que a corrupção é maior; presídios dos quais é mais fácil fugir;

presídios nos quais estão detentos afetivamente mais próximos;

presídios mais próximos de familiares;

presídios com melhores instalações físicas;

presídios em que as práticas violentas não são a regra.

A autora relata, ainda, que, se as possibilidades acima sugeridas não se aplicarem a algum caso em particular, isso não é problemático. É possível considerar que, por razões que mesclam aspectos pessoais, defensivos, estratégicos e de simples busca de algum mínimo sinal de que as coisas podem mudar, a transferência pode ser desejada como forma de ter acesso a qualquer coisa que seja diferente disso aqui.

É como parte dessa "lógica" que as rebeliões podem significar, ainda, através da reunião de presos em grupos para a organização prévia do motim e da transferência que produzem, possibilidades de vivenciar experiências em outros presídios, com variados propósitos. Em outras palavras, as rebeliões podem servir a propósitos pessoais (exploratórios e talvez erráticos) de alguns presos (mais provavelmente, daqueles que não se apresentam orientados para a reconstrução de suas vidas após o cumprimento das penas), visando a aumentar a chance de experimentarem maior variabilidade de situações, de apostar, pela adesão a qualquer oportunidade, na possibilidade de mudanças nas condições em que estão vivendo e, com isso, convencerem-se a si mesmos de que suas vidas provisoriamente encerradas atrás das grades não estão definitivamente encerradas no mundo. Dito ainda de outra forma, mesmo sob condições bastante adversas, esses presos procuram, com as rebeliões, perseguir o propósito de justificarem suas vidas, de construírem significados em torno de suas biografias, tal como faz qualquer ser humano "em liberdade", e, adicionalmente, no caso dos homens, com o propósito de afirmarem vigor, esperteza, masculinidade, e, com isso, continuarem acreditando na autonomia perdida. $\mathrm{Na}$ visão de quem está de fora, pode parecer ilógico, mas qual lógica deve presidir a movimentação de quem não vê saída ou não sabe o que fazer se chegar a sair? Qualquer coisa diferente do que estava vigorando imediatamente antes pode ser melhor, e isso é lógico.

\section{Considerações Finais}

Qualquer coisa que aconteça dentro de uma prisão não se relaciona exclusivamente com as condições de funcionamento de tal prisão. Relaciona-se, também, com as condições que produziram os protagonistas dos atos que resultaram em encarceramento (condições sociais, econômicas, culturais, familiares, escolares), com as interfaces conhecimento/ignorância, compreensão/ alienação, sociabilidade/violência e esperança/ desesperança, que cada interno atingiu e traz para dentro da prisão, e relaciona-se, ainda, com as políticas públicas ligadas à segurança, à educação, à assistência às famílias, à geração de empregos, à questão agrária e aos fluxos migratórios.

A maior parte dos brasileiros encarcerados em prisões comuns viveram em condições similares, partilhando o mesmo conjunto de carências, de mazelas, de falta de qualquer horizonte de perspectivas, sem poder de ação e de representação. Tais detentos nasceram e foram criados nessa realidade e muito cedo envolveramse nos episódios que culminaram na sua detenção. É certo que outros jovens, nascidos e criados naquelas mesmas condições, não reagirão da mesma forma a essa realidade que pode ser bem caracterizada como sendo de exclusão. Isso é compreensível, uma vez que

A dialética inclusão/exclusão gesta subjetividades específicas que vão desde o sentir-se incluído até o sentir-se discriminado ou revoltado. Essas subjetividades não podem ser explicadas unicamente pela determinação econômica, elas determinam e são determinadas por formas diferenciadas de legitimação social e individual, e manifestam-se no cotidiano como identidade, sociabilidade, afetividade, consciência e inconsciência (Sawaia, 1999a, p. 09).

Com a noção de exclusão (ou a da dialética exclusão/inclusão, como destacou Sawaia, sublinhando o caráter relacional e processual do fenômeno em questão, que admite, inclusive, que muitas modalidades de inclusão são, em si mesmas, excludentes), pode-se descrever um processo multidimensional no qual estão em jogo dimensões materiais e políticas de movimentação e acessibilidades sociais, culturais, relacionais e subjetivas. É nesse sentido que Sawaia (1999a) considera a exclusão como processo sutil e dialético que, portanto, existe como parte constitutiva da inclusão, como produto do funcionamento do sistema social, enfim, como um processo que envolve o homem e suas relações com os outros, e não como sendo uma "falha" do sistema ou como possuidora de uma única forma.
Em todos os relatos, 0 tempo de morrer é um tempo na voz passiva. Nele as pessoas não têm poder algum sobre si e sobre os acontecimentos. A imagem mais usada para descrevê-lo é a de prisão, cujas grades são as relações que compõemo cotidiano das pessoas. [...] No tempo de morrer, o sofrimento é a vivência depressiva que condensa os sentimentos de indignidade, inutilidade e desqualificação

Sawaia 
O processo atinge indivíduos concretos, e não categorias sociológicas, acarretando diferentes sofrimentos em todas as esferas da vida desses indivíduos. A mesma autora citada acima, em outro texto, deixa isso muito claro, ao dizer que "é o indivíduo que sofre, porém, esse sofrimento não tem a gênese nele, e, sim, em intersubjetividades delineadas socialmente" (Sawaia, 1999b, p. 99). Faz pouco sentido, em nossa realidade, pensar na prisão como mecanismo de re-inclusão. Ela acaba funcionando, por ainda acrescentar um elemento de estigmatização, como um mecanismo "oficializador" da exclusão, como um atestado de exclusão com firma reconhecida. Estar na prisão e agir com propósito, construir projetos, é pouco provável. Parece mais provável apenas ser levado à reação ocasional ou ser coagido. Nesse sentido, vale a pena citar um estudo com mulheres que viviam em condições subumanas, no qual elas falavam em "tempo de morrer", como metáfora para um certo tipo de vida, inclusive a vida carcerária. A pesquisadora responsável pelo estudo afirma que

Em todos os relatos, o tempo de morrer é um tempo na voz passiva. Nele as pessoas não têm poder algum sobre si e sobre os acontecimentos. A imagem mais usada para descrevê-lo é a de prisão, cujas grades são as relações que compõem o cotidiano das pessoas. [...] No tempo de morrer, o sofrimento é a vivência depressiva que condensa os sentimentos de indignidade, inutilidade e desqualificação (Sawaia, 1995, p.159).

A vivência da exclusão é tão marcante, tão impregnadora das relações sociais, que anula a própria distinção entre estar na rua e estar na prisão, redimensionando a idéia de liberdade de ir e vir. Dizemos isso tomando como base uma constatação de Sawaia (1999b) a partir de um estudo com moradores de rua. Registra a autora:

O sofrimento deles revela o processo de exclusão afetando o corpo e a alma, com muito sofrimento, sendo o maior deles o descrédito social, que os atormenta mais que a fome. $O$ brado angustiante do eu quero ser gente perpassa o subtexto de todos os discursos. E ele não é apenas o desejo de igualarse, mas de distinguir-se e ser reconhecido (p.115, itálicos no original).

Acreditamos que o mesmo texto poderia aplicarse aos presos. Os presidiários brasileiros, que fazem um trajeto de vida marcado pela exclusão social, com alternativas mínimas, expressam, inclusive através das rebeliões, o desejo de ser gente e a angústia de se sentir inferior, sem valor, sem reconhecimento social.
Gilead Marchezi Tavares \& Paulo Rogério Meira Menandro Rua Três Irmãos, n. 605, Vila Garrido, Vila Velha/ES. CEP: 29116-680. Telefone: (27)3359-1736 / (27)9989-6078. E-mail: gilead.dindin@ig.com.br 
ADORNO, S. Sistema Penitenciário no Brasil. Revista USP, SP, n. 9, 1991, pp. 65-78.

ADORNO, S. Insegurança Versus Direitos Humanos: Entre a Lei e a Ordem. Tempo Social. Revista Sociologia da USP, SP, v. 11, n. 2, 2000, pp. 129-153.

ADORNO, S.; CARDIA, N. Dilemas do Controle Democrático da Violência: Execuções Sumárias e Grupos de Extermínio. São Paulo (Brasil), 1980-1989. In Santos, J. V. T. (org.). Violência em Tempo de Globalização. São Paulo: Hucitec, 1999.

BARTOL, C. R. Criminal Behavior - a Psychosocial Approach. Englewood Cliffs: Prentice Hall, 1991.

BAUMAN, Z. Globalização: as Conseqüências Humanas. Rio de Janeiro: Jorge Zahar, 1999.

BENEVIDES, M. V. Violência, Povo e Polícia Violência Urbana no Noticiário de Imprensa). São Paulo: Brasiliense, 1983.

BRASIL. Decreto-lei n. 2848, de 7 de dezembro de 1940 (atualizado e acompanhado de legislação complementar). Código Penal.

BRASIL. Lei n. 7210, de 11 de julho de 1984. Lei de Execução Penal.

CALDEIRA, T. P. R. Direitos Humanos ou "Privilégios de Bandidos"? Desventuras da Democratização Brasileira. Novos Estudos, CEBRAP SP, n. 30, 1991, pp. 162-174.

CASTRO, M. M. P. Ciranda do Medo. Revista USP, SP, n. 9, 1991, pp. $57-64$

COELHO, E. C. A Oficina do Diabo; Crise e Conflitos no Sistema Penitenciário do Rio de Janeiro. Rio de Janeiro: Espaço e Tempo/ IUPERJ, 1987.

DAMATTA, R. Carnavais, Malandros e Heróis: Para uma Sociologia do Dilema Brasileiro. 6. ed. Rio de Janeiro: Rocco, 1997.

EITZEN, D. S.; TIMMER, D. A. Criminology. New York: John Wiley and Sons, 1985.

FRAGOSO, H. Direito Penal e Direitos Humanos. Rio de Janeiro: Forense, 1977.

GOFFMAN, E. Manicômios, Prisões e Conventos. 3. ed. São Paulo: Perspectiva, 1990

HANEY, C.; BANKS, C.; ZIMBARDO, P. B. . Interpersonal Dynamics in a Simulated Prison. International Journal of Criminology and Penology, n. 1,1973

HERKENHOFF, J. B. Crime, Tratamento sem Castigo. Petrópolis: Vozes, 1987.

HUMAN RIGHTS WATCH, HRW. Relatório: o Brasil Atrás das Grades (online). Disponível em: < http://hrw.com >, 1998. Acesso em: 09 fev 2001.

ILANUD. Incidentes Prisionais: Principais Características e Formas de Evitá-los. Revista do ILANUD. São Paulo, n. 09, 1998, pp. 16-39.

IANKOWSKI, M. S. Island in the Street: Gangs and American Urban Society. Berkeley, CL: University of California Press, 1991.

KAHN, T. Sistema Penitenciário: Mudanças de Perfil dos Anos 50 aos 90. Revista do ILANUD. São Paulo, n. 06, 1997, pp. 1-30.

MACHADO, M. L; MARQUES, B. A. História de um Massacre: Casa de Detenção de São Paulo. São Paulo: Cortez: OAB, 1993.

MARQUES, J. B. A. Gerenciamento de Crises no Sistema Prisional. Revista do ILANUD. São Paulo, n. 05, 1999, pp. 1-20.

MENANDRO, P. R. M. A Questão Carcerária: um Problema Técnico? Arquivos Brasileiros de Psicologia, Rio de Janeiro, v. 36, n. 3, 1984, pp. $62-89$
MINISTÉRIO DA JUSTIÇA. SECRETARIA NACIONAL DE JUSTIÇA. DEPARTAMENTO PENITENCIÁRIO NACIONAL. Dados Consolidados - Total Brasil. Dezembro de 2000 (online). Disponível em: <http:// depen.com >. Acesso em: 07 fev. 2001.

MORIN, E. O Homem e a Morte. Rio de Janeiro: Imago, 1997.

ORGANIZAÇÃO DAS NAÇÕES UNIDAS, ONU. Relatório Sobre Tortura no Brasil, Produzido pelo Relator Especial da Comissão de Direitos Humanos da ONU Sobre Tortura. Genebra, 11 abr. 2001 (online). Disponível em: <http://onu.com >. Acesso em: 21 mai. 2001.

PERALVA, A. . Juvenização da Violência e Angústia da Morte. Trabalho apresentado no XX ENCONTRO ANUAL DA ANPOCS, Caxambu, 1996.

PINHEIRO, P. S. Algumas Considerações Sociopolíticas Sobre Presose Prisões. In Queiroz, J. J. (org.). As Prisões, os Jovens e o Povo. São Paulo: Paulinas, 1985.

RAMALHO, J. R. Mundo do Crime: a Ordem Pelo Avesso. Rio de Janeiro: Graal, 1979

RIOS, J. A Motins em Prisões: seus Fatores e Possibilidades de Prevenilos. Revista do ILANUD. São Paulo, n. 09, 1998, pp. 1-15.

ROSE, S. A Perturbadora Ascensão do Determinismo Neurogenético. Revista Ciência Hoje, v. 21, n. 126, 1997, pp.18-27.

SARUBBI, A.; REZENDE, A. F. C. Sistema Prisional na Europa. Modelo Para o Brasil? São Paulo: Peritas, 1997.

SAWAIA, B. B. Dimensão Ético-afetiva do Adoecer da Classe Trabalhadora. In Lane, S. T. M.; Sawaia, B. B. (orgs.). Novas Veredas da Psicologia Social. São Paulo: EDUC/Brasiliense, 1995.

Exclusão ou Inclusão Perversa? In Sawaia, B. B. (org.) As Artimanhas da Exclusão: Análise Psicossocial e Ética da Desigualdade Social. Petrópolis: Vozes, 1999a.

O Sofrimento Ético-político Como Categoria de Análise da Dialética Exclusão/Inclusão. In Sawaia, B. B. (org.). As Artimanhas da Exclusão: Análise Psicossocial e Ética da Desigualdade Social. Petrópolis: Vozes, 1999 b.

TAVARES, G. M. Características e Significados de Rebeliões em Prisões Brasileiras: um Estudo a Partir de Material Jornalístico. Dissertação de Mestrado em Psicologia - Programa de Pós-Graduação em Psicologia. Universidade Federal do Espírito Santo, Vitória, 2001, 119 f.

TAYLOR, I.; WALTON, P.; YOUNG, J. Criminologia Crítica. Rio de Janeiro: Graal, 1980

THOMPSON, A. F. G. AQuestão Penitenciária. Petrópolis: Vozes, 1976.

THOMPSON, A. F. G. Quem São os Criminosos? Rio de Janeiro: Achiamé, 1983.

VARELLA, D. Estação Carandiru. São Paulo: Companhia da Letras, 1999.

VELHO, G. Violência, Reciprocidade e Desigualdade: uma Perspectiva Antropológica. In Velho, G; Alvito, M. (orgs.). Cidadania e Violência. Rio de Janeiro: UFRJ: FGV, 1996.

WACQUANT, L. As Prisões da Miséria. Rio de Janeiro: Jorge Zahar, 2001.

WANDERLEY, M. B. Refletindo Sobre a Noção de Exclusão. In Sawaia, B. B. (org.). As Artimanhas da Exclusão: Análise Psicossocial e Ética da Desigualdade Social. Petrópolis: Vozes, 1999.

ZALUAR, A. Da Revolta ao Crime S. A. São Paulo: Moderna, 1996a

A Globalização do Crime e os Limites da Explicação Local. In Velho, G; Alvito, M. (orgs.). Cidadania e Violência. Rio de Janeiro: UFRJ: FGV, 1996b.
Referências 